\title{
Cytotoxicity, anti-angiogenic, apoptotic effects and transcript profiling of a naturally occurring naphthyl butenone, guieranone $\mathrm{A}$
}

\author{
Victor Kuete ${ }^{1,2^{*}}$, Tolga Eichhorn ${ }^{2}$, Benjamin Wiench ${ }^{2}$, Benjamin Krusche ${ }^{2}$ and Thomas Efferth ${ }^{2 *}$
}

\begin{abstract}
Background: Malignant diseases are responsible of approximately 13\% of all deaths each year in the world. Natural products represent a valuable source for the development of novel anticancer drugs. The present study was aimed at evaluating the cytotoxicity of a naphtyl butanone isolated from the leaves of Guiera senegalensis, guieranone A (GA).

Results: The results indicated that GA was active on $91.67 \%$ of the 12 tested cancer cell lines, the $I_{50}$ values below $4 \mu \mathrm{g} / \mathrm{ml}$ being recorded on $83.33 \%$ of them. In addition, the $\mathrm{IC}_{50}$ values obtained on human lymphoblastic leukemia CCRF-CEM $(0.73 \mu \mathrm{g} / \mathrm{ml})$ and its resistant subline CEM/ADR5000 $(1.01 \mu \mathrm{g} / \mathrm{ml})$ and on lung adenocarcinoma A549 $(0.72 \mu \mathrm{g} / \mathrm{ml})$ cell lines were closer or lower than that of doxorubicin. Interestingly, low cytotoxicity to normal hepatocyte, AML12 cell line was observed. GA showed anti-angiogenic activity with up to $51.9 \%$ inhibition of the growth of blood capillaries on the chorioallantoic membrane of quail embryo. Its also induced apotosis and cell cycle arrest. Ingenuity Pathway Analysis identified several pathways in CCRF-CEM cells and functional group of genes regulated upon GA treatment $(P<0.05)$, the Cell Cycle: G2/M DNA Damage Checkpoint Regulation and ATM Signaling pathways being amongst the four most involved functional groups.
\end{abstract}

Conclusion: The overall results of this work provide evidence of the cytotoxic potential of GA and supportive data for its possible use in cancer chemotherapy.

Keywords: Angiogensis, Apoptosis, Cytotoxicity, Guieranone A, Microarray, Pharmacogenomics

\section{Background}

Malignant diseases are responsible of approximately 13\% of all deaths each year in the world. About 12.7 million cancer cases and 7.6 million cancer deaths are estimated to have occurred in 2008; of these, $56 \%$ of the cases and $64 \%$ of the deaths occurred in the economically developing world [1]. Breast cancer is the most frequently diagnosed cancer and the leading cause of cancer death among females, accounting for $23 \%$ of the total cancer cases and $14 \%$ of the cancer deaths; Lung cancer is the leading cancer site in males, comprising $17 \%$ of the total new cancer cases and 23\% of the total cancer deaths [1]. It is reported that cancer is the leading cause of death in

\footnotetext{
* Correspondence: kuetevictor@yahoo.fr; efferth@uniainz.de

'Department of Biochemistry, Faculty of science, University of Dschang, Dschang, Cameroon

${ }^{2}$ Department of Pharmaceutical Biology, Institute of Pharmacy and Biochemistry, University of Mainz, Staudinger Weg 5, 55128, Mainz, Germany
}

the developed world and the second leading cause of death in the developing world [1]. In 2000, leukemia represented about $3 \%$ of the almost seven million deaths due to cancer that year, and about $0.35 \%$ of all deaths from any cause [2]. Natural products represent a valuable source for the development of novel anticancer drugs. The present study was focused on the cytotoxic potential of a naphtyl butanone, a major component of the leaves of Guiera senegalensis, GA. This compound previously showed good antifungal activity against Cladosporium сисumerinum [3], strong antiplasmodial activity and high cytotoxicity towards two cancer cell lines: HCT-116 colon carcinoma and THP-1 human acute monocytic leukemia [4]. Interestingly, the complete chemical synthesis of GA was reported [5]. Therefore, we undertook the present work to highlight the anticancer potential of this compound and its possible effects on cell cycle distribution, apoptosis, 
transcript profiling using leukemia CCRF-CEM cells as a model. The study was also extended to the search of the anti-angiogenic potency of GA.

\section{Methods}

\section{Chemical for cytotoxicity assay}

Doxorubicin (Sigma-Aldrich, Schnelldorf, Germany) was used as a positive (cytotoxic) control. Captopril (SigmaAldrich) was used as positive anti-angiogenic control. GA was isolated from the methanol extract from the leaves of Guiera senegalensis; The leaves of the plant were collected in Mount Kala (Centre Region of Cameroon, Africa) in May 2008. The plant was identified at the Cameroon National Hebarium (Yaounde) were a voucher specimen was deposited. The air-dried and powdered leaves $(1.5 \mathrm{~kg})$ were soaked in $6 \mathrm{~L}$ of methanol for $48 \mathrm{~h}$, at room temperature. The methanol extract was concentrated under reduced pressure to give $120 \mathrm{~g}$ of a Green-dark residue that constituted the crude extract (GSL). Part of this extract (100 g) was submitted to repeated silica gel $60(0.04-0.063 \mathrm{~mm}, 200 \mathrm{~g})$ and thin layer chromatography (TLC) to afforded $\mathrm{GA} \mathrm{C}_{18} \mathrm{H}_{20} \mathrm{O}_{5}$ (light yellow crystals; $48 \mathrm{mg} ; \mathrm{m} / \mathrm{z}$ 316; m.p. $99-101^{\circ} \mathrm{C}$ ) $[3,6]$ (Detailed isolation and general experimental procedures are available as Supporting information).

\section{Cell lines treatment}

A panel of fourteen cancer cell lines including human lymphoblastic CCRF-CEM leukemia cells and their multidrug-resistant subline, CEM/ADR5000, MiaPaCa-2 and Capan-1 pancreatic adenocarninoma cells, MCF-7 breast adenocarcinoma cells, SW-680 colon carcinoma cells, 786-0 renal carcinoma cells, U87MG glioblastoma cells, A549 lung adenocarcinoma cells, Caski and HeLa cervical carcinoma cells, Colo-38 skin melanoma cells, as well as AML12 normal hepatocytes were used. Cell lines were obtained from different sources: Prof. Axel Sauerbrey, University of Jena, Jena, Germany (CCRFCEM, CEM/ADR5000), Dr. Jörg Hoheisel, German Cancer Research Center, Heidelberg, Germany (MiaPaCa-2, Capan-1, MCF-7, SW-680), Tumor Bank, German Cancer Research Center, Heidelberg, Germany (786-0, U87MG, A549, Caski, HeLa, Colo-38), American Type Culture Collection,USA (AML12).

All cell lines were maintained in RPMI 1640 containing 100 units $/ \mathrm{ml}$ penicillin and $100 \mu \mathrm{g} / \mathrm{ml}$ streptomycin and supplemented with heat-inactivated $10 \%$ fetal bovine serum (FBS). All cultured cells were maintained in a humidified incubator at $37^{\circ} \mathrm{C}$ with $5 \% \mathrm{CO}_{2}$. Multidrug resistance of CEM/ADR5000 was maintained by applying $5000 \mathrm{ng} / \mathrm{ml}$ Doxorubicin every other cell passage. Doxorubicin (Sigma-Aldrich, Schnelldorf, Germany) was used as a positive (cytotoxic) control. The concentration of DMSO was kept at or below $0.1 \%$ in all experiments.

\section{Resazurin cell growth inhibition assay}

Alamar Blue or Resazurin (Promega, Mannheim, Germany) reduction assay [7] was used to assess the cytotoxicity of the studied samples. Doxorubicin was used as positive control. Each assay was done at least three times, with two replicate each. The viability after $48 \mathrm{~h}$ was compared based on a comparison with untreated cells. $\mathrm{IC}_{50}$ (on cancer cells) or $\mathrm{EC}_{50}$ (on AML12 cells) values were the concentration of sample required to inhibit $50 \%$ of the cell proliferation and was calculated from a calibration curve by a linear regression [8], using Microsoft Excel (The detailed Resazurin assay is available in Supporting information).

\section{Flow cytometry for cell cycle analysis and detection of apoptotic cells}

Leukemia CCRF-CEM cells treated with GA or DMSO (solvent control) for 24 to $72 \mathrm{~h}$ were fixed with ethanol 95\% and washed with cold, phosphate-buffered saline (PBS; Invitrogen) and then resuspended in $150 \mu \mathrm{l}$ hypotonic fluorochrome solution $(50 \mu \mathrm{g} / \mathrm{ml}$ propidium iodide, $10 \mu \mathrm{g} / \mathrm{ml}$ RNAse A in PBS). The cells were incubated in the dark at $4^{\circ} \mathrm{C}$ overnight before flow-cytometry analysis was performed. The propidium iodide fluorescence of individual nuclei was measured using a FACS-Calibur cytometer (BD Biosciences, Heidelberg, Germany). Data were analyzed with the CellQuess Pro V5.2.1 software (BD Biosciences). For each condition, at least three independent experiments were performed.

\section{Caspase-glo 3/7 assay}

The influence of GA on caspase 3/7 activity in CCRFCEM leukemia cells was detected using Caspase-Glo 3/7 Assay kit (Promega). Cells cultured in RPMI were seeded in 96-well plates and treated with the sample $\left(2 \times \mathrm{IC}_{50}\right.$; $\mathrm{IC}_{50} ; 1 / 2 \times \mathrm{IC}_{50}$ ) or DMSO (solvent control). After $24 \mathrm{~h}$ treatment, $100 \mu \mathrm{l}$ of caspase $3 / 7$ reagent were added to each well, mixed and incubated for $1 \mathrm{~h}$ at room temperature. Luminescence was measured using well Infinite M2000 Pro $^{\text {Tx }}$ instrument (Tecan). Caspase 3/7 activity was expressed as percentage of the untreated control.

\section{Detection of angiogenesis in vivo by cultivation of quail eggs}

The quail eggs were purchased from Wachtelzucht Anne Klein, Steinhagen, Germany. The embryos were cultured according to the method described by Wittmann et al. [9]. GA and captopril (as positive control drug) were tested for their anti-angiogenic effects at $20 \mu \mathrm{g} / \mathrm{ml}$, using chicken chorioallantoic membrane assay (CAM assay) method as described by D'Arcy and Howard [10], with modifications according to Marchesan et al. [11]. The percentage inhibition of vascularization was calculated 
as previously described [12] (Detailed anti-angiogenic tests are available in Supporting information).

\section{mRNA-based microarray expression profiling} RNA isolation and analysis

Total RNA from CCRF-CEM cells was isolated using RNeasy Kit from Qiagen (Hilden, Germany) according to the manufacture's instruction. RNA was resuspended/ eluted in TE/water. The quality of total RNA was checked by gel analysis using the total RNA Nano chip assay on an Agilent 2100 Bioanalyzer (Agilent Technologies $\mathrm{GmbH}$, Berlin, Germany). Only samples with RNA index values greater than 8.5 were selected for expression profiling. RNA concentrations were determined using the NanoDrop spectrophotometer (NanoDrop Technologies, Wilmington, DE).

\section{Probe labeling and illumina sentrix BeadChip array hybridization}

Biotin-labeled cRNA samples for hybridization on Illumina Human Sentrix-HT12 BeadChip arrays (Illumina, Inc.) were prepared according to Illumina's recommended sample labeling procedure based on the modified Eberwine protocol [13] (Detailed tests is available in Supportive information).

\section{Scanning and data analysis}

Microarray scanning was done using a Beadstation array scanner, setting adjusted to a scaling factor of 1 and PMT settings at 430. Data extraction was done for all beads individually, and outliers are removed when $>2.5$ MAD (median absolute deviation). All remaining data points are used for the calculation of the mean average signal for a given probe, and standard deviation for each probe was calculated.

Data analysis was done by normalization of the signals using the quantile normalization algorithm without background subtraction, and differentially regulated genes are defined by calculating the standard deviation differences of a given probe in one-by-one comparisons of samples or groups.

All data is MIAME compliant and the raw data has been deposited in a MIAME compliant database as detailed on the MGED Society website http://www.ebi.ac.uk/arrayexpress/experiments/E-MTAB-731 (Accession number EMTAB-731).

\section{Real-time (RT)-PCR}

The same RNA samples used for microarray experiment were also used for RT-PCR experiments. RNA samples extracted from cells treated with GA or DMSO (solvent control) were converted to cDNA by reverse transcriptase (Invitrogen) using random hexamerprimers. The cDNAs were quantified by real-time PCR using the
SsoFast EvaGreen PCR Kit (Bio-RAD, München, Germany) and the CFX384 ${ }^{\mathrm{TM}}$ Real-Time PCR Detection Systems (Bio-RAD), PCR was done by initial incubation at $50^{\circ} \mathrm{C}$ for $10 \mathrm{~min}$, denaturation at $95^{\circ} \mathrm{C}$ for $5 \mathrm{~min}$ and 40 cycles were performed in two steps for each: denaturation at $95^{\circ} \mathrm{C}$ for $30 \mathrm{~s}$, annealing at $62^{\circ} \mathrm{C}$ for $40 \mathrm{~s}$. Melt Curve was performed by cooling from $95^{\circ} \mathrm{C}$ to $65^{\circ} \mathrm{C}$, followed by a gradual increase in temperature $\left(0.5^{\circ} \mathrm{C} / 5 \mathrm{~s}\right)$ to $95^{\circ} \mathrm{C}$. Expression levels were normalized relative to the transcription level of G6PD. All samples were run in triplicate.

\section{Statistical analysis}

Statistical analysis of all data was performed using a Student's $t$-test or Kruskal-Wallis test followed by Dunn's post-hoc multiple comparison test (Graph-Pad Prism 5.01; GraphPad Software, Inc., CA, USA). $P<0.05$ denoted significance in all cases.

\section{Results}

\section{Cytotoxicity}

The results of the cytotoxicity of GA on a panel of cancer cell lines are summarized in Table 1. More than $50 \%$ inhibition of proliferation after $48 \mathrm{~h}$ treatment were obtained for eleven of the twelve studied (91.67\%) cancer cell lines, with $\mathrm{IC}_{50}$ values below $20 \mu \mathrm{g} / \mathrm{ml}$. At the concentration of $20 \mu \mathrm{g} / \mathrm{ml}$, GA did not induced the proliferation of up to $50 \%$ for colon SW-680 cell lines as well as for normal AML12 cells (Table 1).

\section{Anti-angiogenic effect of guieranone A}

In the present study, GA showed $51.9 \%$ inhibition of blood capillary growth on the chorioallantoic membrane of quail eggs (Figure 1). However, the anti-angiogenic effect of GA was still lower than that of the reference compound, captopril (76.46\% inhibition).

\section{Cell cycle analysis and apoptosis}

The flow cytometry data (Figure 2) indicate that GA did not significantly induce apoptosis in the early phase after treatment of CRRF-CEM cells ( $24 \mathrm{~h})$, but that the cells progressively underwent apoptosis in a time- and dosedependent manner (up to $30.19 \%$ apoptosis after $72 \mathrm{~h}$ at $2 \times \mathrm{IC}_{50}$ treatment), and significant reduction of cells in G0/G1 phase and cell cycle arrest betwen $S$ and G2/M phase. This compound also induced low caspase 3/7 activity (Additional file 1: Figure S1) in CCRF-CEM cells after $6 \mathrm{~h}$.

\section{Microarray analysis and signaling pathway profiling}

To identify pathways and possible molecular targets involved in the antitumor effect of GA, CCRF-CEM cells were then treated with this compound and subjected to 
Table 1 Cytotoxicity of Guieranone A and Doxorubicin in various cancer cell lines

\begin{tabular}{|c|c|c|c|c|}
\hline \multirow[t]{3}{*}{ Cell lines } & \multicolumn{4}{|c|}{ Sample and $I C_{50}$ values } \\
\hline & \multicolumn{2}{|l|}{ Guieranone A } & \multicolumn{2}{|l|}{ Doxorubicin } \\
\hline & $\mu \mathrm{g} / \mathrm{ml}$ & $\mu \mathrm{M}$ & $\mu \mathrm{g} / \mathrm{ml}$ & $\mu \mathrm{M}$ \\
\hline CCRF-CEM & $0.73 \pm 0.11$ & $2.31 \pm 0.35$ & $0.62 \pm 0.003$ & $1.14 \pm 0.005$ \\
\hline CEM/ADR5000 & $1.01 \pm 0.09(1.38)$ & $3.19 \pm 0.28$ & $>20(>32.26)$ & $>36.8$ \\
\hline MiaPaCa-2 & $3.91 \pm 0.25$ & $12.37 \pm 0.79$ & $0.95 \pm 0.06$ & $1.75 \pm 0.11$ \\
\hline Capan-1 & $9.19 \pm 2.29$ & $29.08 \pm 7.24$ & $4.06 \pm 1.18$ & $7.47 \pm 2.17$ \\
\hline MCF-7 & $1.08 \pm 0.32$ & $3.42 \pm 0.90$ & $0.59 \pm 0.05$ & $1.08 \pm 0.09$ \\
\hline SW-680 & $>20$ & $>63.29$ & $0.93 \pm 0.09$ & $1.71 \pm 0.17$ \\
\hline $786-0$ & $3.68 \pm 0.54$ & $11.32 \pm 1.70$ & $0.60 \pm 0.09$ & $1.10 \pm 0.17$ \\
\hline U87MG & $2.46 \pm 0.02$ & $7.78 \pm 0.05$ & $0.37 \pm 0.08$ & $0.68 \pm 0.14$ \\
\hline A549 & $0.72 \pm 0.07$ & $2.28 \pm 0.22$ & $1.69 \pm 0.05$ & $3.11 \pm 0.09$ \\
\hline Colo-38 & $2.43 \pm 0.75$ & $7.69 \pm 1.38$ & $0.81 \pm 0.06$ & $1.49 \pm 0.11$ \\
\hline HeLa & $0.51 \pm 0.04$ & $1.61 \pm 0.13$ & $0.26 \pm 0.02$ & $0.48 \pm 0.04$ \\
\hline Caski & $1.18 \pm 0.11$ & $3.73 \pm 0.35$ & $0.58 \pm 0.02$ & $1.07 \pm 0.04$ \\
\hline $\operatorname{AML} 12\left(E_{50}\right)^{*}$ & $>20$ & $>63.29$ & $>20$ & $>36.8$ \\
\hline
\end{tabular}

$\mathrm{ac}^{*} \mathrm{EC}_{50}$ : effective dose showing $50 \%$ inhibition of growth proliferation.

mRNA-based microarray hybridization. The top 10 up- or down-regulated genes out of 227 genes (see Additional file 1: Table S2) upon GA treatment in CCRF-CEM cells are summarized in Table 2.
The Ingenuity Pathway Analysis (version 6.5) identified several pathways (Additional file 1: Tables S3 and S4) and functional group of genes in CCRF-CEM cells which were regulated upon GA treatment
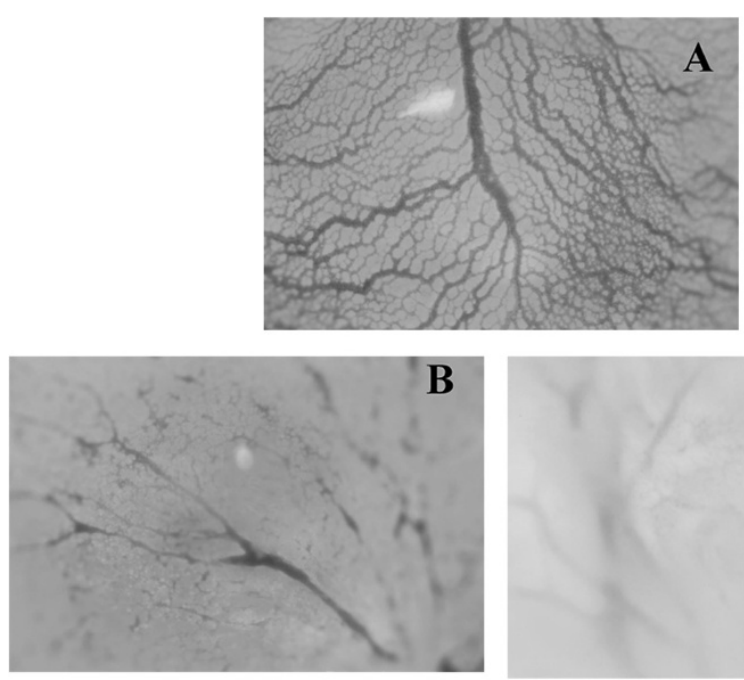

C

Figure 1 Effects of Guieranone A (at $20 \mu \mathrm{g} / \mathrm{ml}$ ) on the growth of blood capillaries on the chorioallantoic membrane of quail eggs. (A) DMSO (control): Normal growth of blood capillaries on the CAM - no antiangiogenic effect; (B): Guieranone A (51.9 $\pm 1,3 \%$ inhibition); (C): Captopril (76.46\% inhibition $\pm 3.6 \%$ ). 


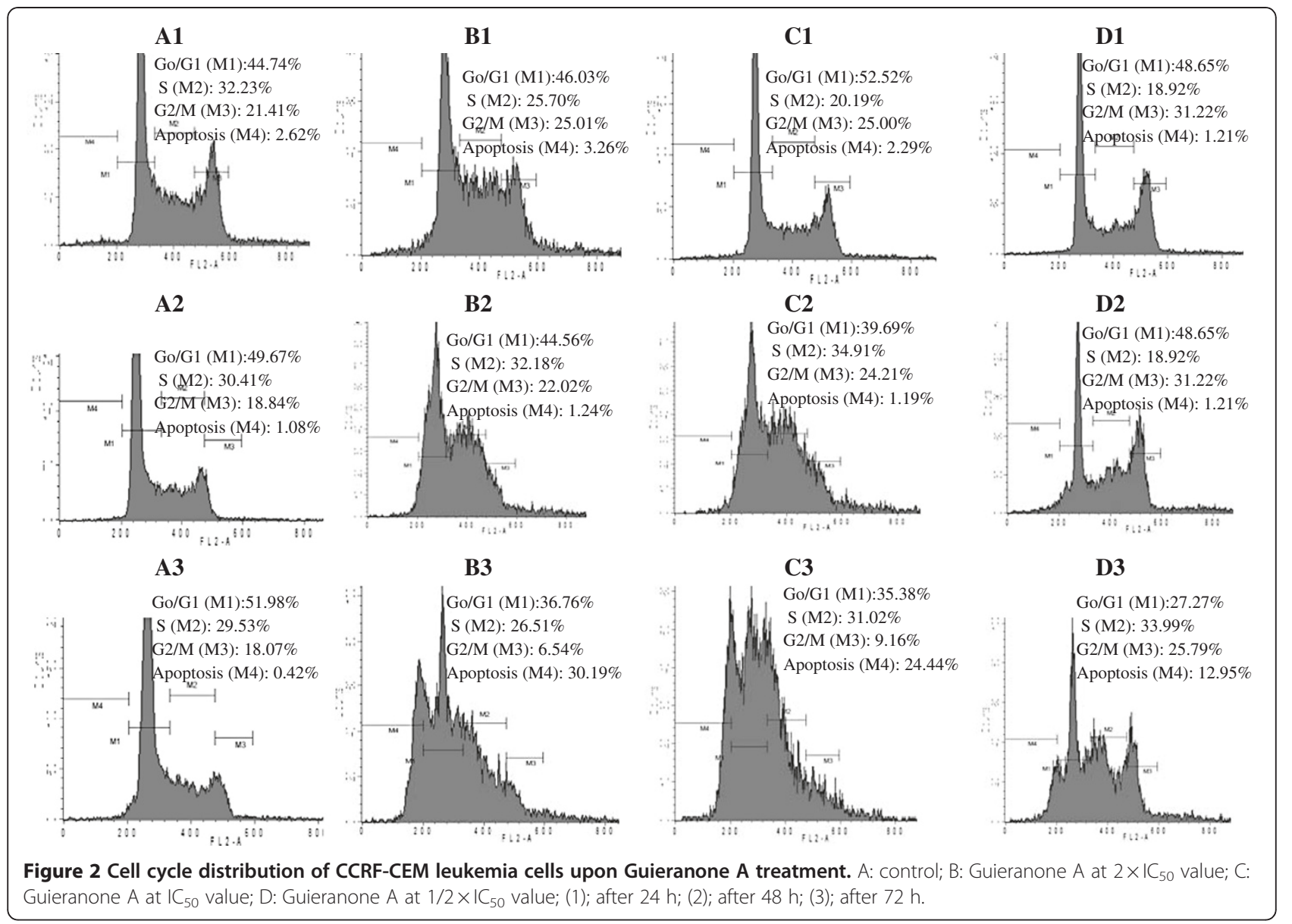

(significance value of $P<0.05)$. Amongst the top four functional groups of genes (Table 3), the Cell Cycle: G2/M DNA Damage Checkpoint Regulation and ATM Signaling pathways (Additional file 1: Figure S1) was directly linked to cancer. CHK1 (Serine/threonineprotein kinase gene; cell cycle control and particularly for entry into mitosis) was found to be downregulated in these two parthways (Additional file 1: Figure S5). In addition WEE1 (nuclear kinase gene; key regulator of cell cycle progression) (Additional file 1: Table S2) is down-regulated in Cell Cycle: G2/M DNA Damage Checkpoint Regulation following GA treatment, giving some explanation on the way of cell death is induced.

The networks representing the four most important functional group of genes affected by GA treatment are illustrated in Figures 3 and 4. The two most upregulated genes are HSPA6 (heat shock $70 \mathrm{kDa}$ protein 6) and HIST1H2BD (histone cluster 1, H2bd) (Table 2, Figure 4A). Further genes of interest which are up-regulated are FOSB and JUN, HIST1H2BD, HIST2H2AC, HIST2H2AA4, CD52 (Table 3). Important down-regulated genes found upon GA treatment were $A C T B$ and ACTBL3, PGAM1, LOC728188,
DHRS2, KPNA2, THOC4, RAB37 and TRAPPC6A, HNRNPK, LYAR and YBX1, LYAR, YBX1, MYCN, RUVBL1 (Figure 3 and 4).

\section{Real time RT-PCR}

To verify the microarray data with a second independent method, RT-PCR was exemplarily performed for some differentially regulated genes (i.e. $A C T B, G A D D 45$, HSP90AB1, LYAR as well as for G6PD as reference). All results were in accordance with the microarray results (see Additional file 1: Figure S6).

\section{Discussion \\ Cytotoxicity}

In the US NCI plant screening program, a compound is generally considered to have in vitro cytotoxic activity, if the $\mathrm{IC}_{50}$ value following incubation between 48 and $72 \mathrm{~h}$, is less than $4 \mu \mathrm{g} / \mathrm{ml}$ or $10 \mu \mathrm{M}$ [14]. In the present work, the $\mathrm{IC}_{50}$ values below $4 \mu \mathrm{g} / \mathrm{ml}$ were recorded on 11/14 (75.57\%) of the studied cancer cells, clearly highlighting the good cytotoxicity potential of GA. In addition, values obtained on CCRFCEM $\left(\mathrm{IC}_{50}\right.$ of $\left.0.73 \mu \mathrm{g} / \mathrm{ml}\right)$ and its multidrug-resistant subline, CEM/ADR5000 $(1.01 \mu \mathrm{g} / \mathrm{ml})$, A549 $(0.72 \mu \mathrm{g} /$ 
Table 2 Ten most down- or up-regulated genes in CCRF-CEM cells after treatment guieranone A

\begin{tabular}{|c|c|c|c|}
\hline ID & Symbol & Description & Fold Change \\
\hline \multicolumn{4}{|c|}{ Up-regulated genes } \\
\hline 160092 & HSPA6 & heat shock 70 kDa protein 6 (HSP70B) & 11.43 \\
\hline 290730 & HIST1H2BD & histone cluster 1, H2bd & 8.00 \\
\hline 7160239 & FOSB & FBJ murine osteosarcoma viral oncogene homolog B & 5.39 \\
\hline 1820592 & HIST2H2AA4 & histone cluster 2, H2aa4 & 4.45 \\
\hline 20129 & CD52 & CD52 molecule & 4.16 \\
\hline 610451 & HIST2H2AA4 & histone cluster 2, H2aa4 & 4.07 \\
\hline 6510367 & $J U N$ & jun oncogene & 3.86 \\
\hline 6660601 & HMOX1 & heme oxygenase (decycling) 1 & 3.64 \\
\hline 1500600 & RAB37 & RAB37, member RAS oncogene family & 3.34 \\
\hline 6860072 & TRAPPC6A & trafficking protein particle complex $6 \mathrm{~A}$ & 3.29 \\
\hline \multicolumn{4}{|c|}{ Down-regulated genes } \\
\hline 2850020 & DHRS2 & dehydrogenase/reductase (SDR family) member 2 & -4.17 \\
\hline 3420400 & KPNA2 & karyopherin alpha 2 (RAG cohort 1, importin alpha 1) & -4.18 \\
\hline 4230196 & KPNA2 & karyopherin alpha 2 (RAG cohort 1, importin alpha 1) & -4.48 \\
\hline 460286 & THOC4 & THO complex 4 & -4.50 \\
\hline 4390315 & HNRNPATP2 & heterogeneous nuclear ribonucleoprotein A1 pseudogene 2 & -4.77 \\
\hline 2750719 & $D D \times 21$ & DEAD (Asp-Glu-Ala-Asp) box polypeptide 21 & -4.91 \\
\hline 4890671 & DHRS2 & dehydrogenase/reductase (SDR family) member 2 & -5.68 \\
\hline 4880646 & ACTBL3 & actin, beta-like 3 & -5.70 \\
\hline 3940592 & PGAM1 & phosphoglycerate mutase 1 (brain) & -5.76 \\
\hline 5270730 & ACTB & actin, beta & -6.50 \\
\hline
\end{tabular}

*Full list of gene in Supplementary Material.

Table 3 Functions associated with the top four group of genes (Figures 3, 4) whose expression was affected by treatment with guieranone $A$ in CCRF-CEM cancer cell lines

\begin{tabular}{|c|c|c|c|c|}
\hline $\begin{array}{l}\text { ID } \\
\text { (Network) }\end{array}$ & Score & $\begin{array}{l}\text { Focus } \\
\text { molecules }\end{array}$ & Top functions* & List of all molecules involved \\
\hline 1 & 50 & 28 & $\begin{array}{l}\text { Molecular transport, Protein } \\
\text { trafficking, Cellular assembly } \\
\text { and organization }\end{array}$ & $\begin{array}{l}\text { ACP1, ATP1A1, DDX21, DDX3X, DOK2, ERK1/2, GC-GCR dimer, GNL3, } \\
\text { Histone h3, Histone h4, HNRNPH1, HNRNPK, Importin alpha, Importin beta, } \\
\text { KPNA2, KPNB1, LARP1, LYAR, NCL, NDRG1, NUP62, NUP153, RANBP1, Rnr, } \\
\text { RRP1B, RRS1, SLBP, THOC4, TNFRSF8, TNPO1, TPX2, TSC22D3, TSR1, } \\
\text { WDR12, YBX1 }\end{array}$ \\
\hline 2 & 50 & 28 & $\begin{array}{l}\text { Drug metabolism, endocrine } \\
\text { System development and } \\
\text { function, lipid metabolism }\end{array}$ & $\begin{array}{l}\text { ACTB, Actin, ACTL6A, Akt, alcohol group acceptor phosphotransferase, } \\
\text { CS, FASN, HMGA1, HNRNPL, HSP90AB1, IARS, IKK (complex), IPO4, KEAP1, } \\
\text { Lamin b, MAP3K8, MCM3, MCM4, MORF4L2, MYCN, ORC6L, PDCD6IP, } \\
\text { PSMD6, PTGES3 (includes EG:10728), RNF4, RPL6, RPL7A (includes EG:6130), } \\
\text { RPS24 (includes EG:6229), RUVBL1, SGK1, SLC38A2, SMC3, Thyroid } \\
\text { hormone receptor, TIP60, TUBB }\end{array}$ \\
\hline
\end{tabular}

$3 \quad 47 \quad 27 \quad$ Cell death, cell-to-cell signaling and interaction, cellular function and maintenance

$4 \quad 4526 \quad$ Cell cycle, cancer,

gastrointestinal disease
14-3-3, ACAT2, AHCY, APIP, ARF3, CD3, CD52, CTPS, FAM83D, FOSB,

FOXO3, GADD45B, HBP1, HNRNPAB, HSPA6, IL10RB, Immunoglobulin, KIF23, LMNB1, Mapk, Mek, MVP, PDGF BB, PId, PPHLN1, PPP1R15A, PRDX3, PRKCB, RBCK1, RGS2, TCR, UTP14A, VIM, YWHAE, YWHAG

ADAR, APC, CCNA2, CDK1, CDKN3, CHEK1, CNOT7, Cyclin A, DHFR, E2f, FBXO5, FEN1, H2AFY, ID2, IFI16, KIAA0101, MAD2L1, MAP2K1/2, methenyltetrahydrofolate cyclohydrolase, methylenetetrahydrofolate dehydrogenase (NADP), Mre11, MTHFD1, MTHFD2, MTHFD1L, NBN, NUSAP1, PI3K (complex), PRIM1, Rb, RFC4, TFDP1, TINF2, TYMS, WEE1, XRCC5 

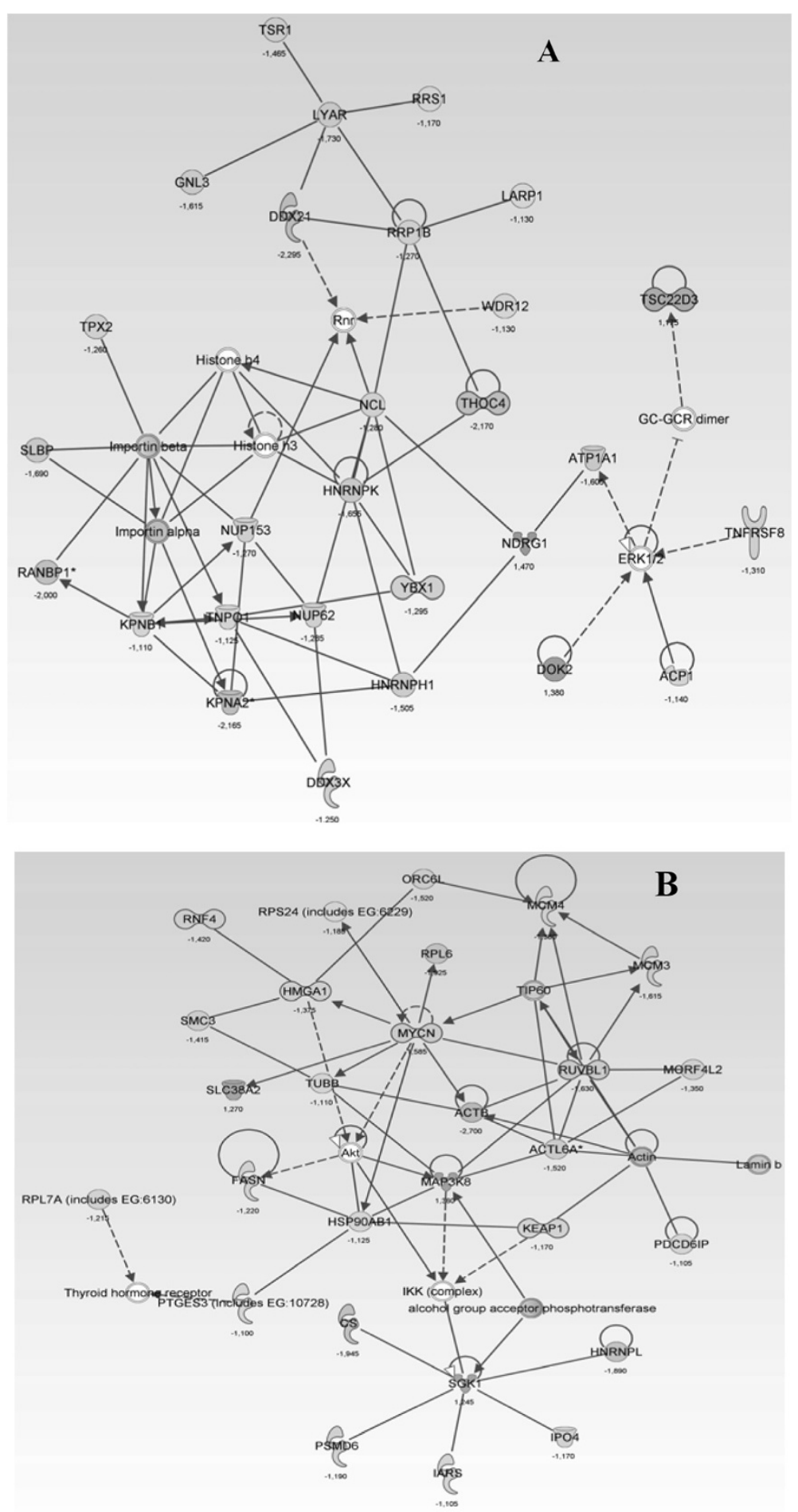

Figure 3 Network of differentially regulated genes upon Guieranone A treatment. (A) Molecular transport, protein trafficking, cellular assembly and organization, (B) Drug metabolism, endocrine system development and function, lipid metabolism. (+): upregulted; (-): downregulated.

$\mathrm{ml}$ ) were closer or lower than that of doxorubicin, clearly confirming this statement. Besides, GA was active on multidrug-resistant CEM/ADR5000 cells, suggesting that this compound might be useful for cancer therapy, including tumor cells resistant to some of the commonly used anticancer drugs. As the 

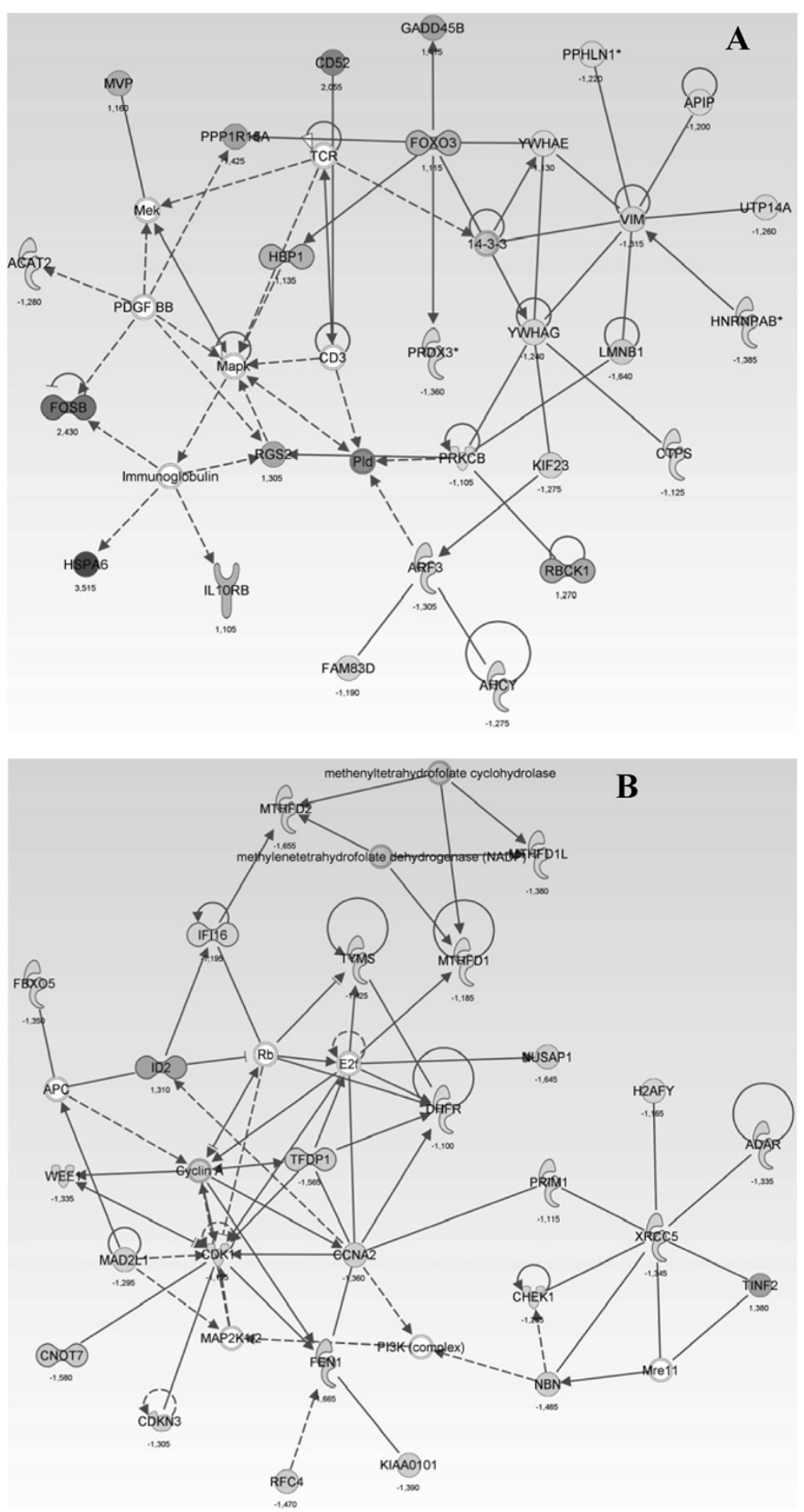

Figure 4 Network of genes of involved (upon guieranone A treatment) in Cell death, cell-to-cell signaling and interaction, cellular function and maintenance (A), and Cell cycle, cancer, gastrointestinal disease (B). (+): upregulted; (-): downregulated.

liver is the main organ involved in drug metabolism, AML12 normal hepatocytes were used to evaluate the cytotoxicity of GA in normal cells. Interestingly, the $\mathrm{EC}_{50}>20 \mu \mathrm{g} / \mathrm{ml}$ obtained was higher than the values obtained against most of the cancer cells (Table 1).
The overall results of the cytotoxicity assay indicated that GA might be a promising candidate as new anticancer drug. Therefore, further studies were conducted to investigate the possible mode of action of this compound. 


\section{Anti-angiogenic effect of guieranone A}

Angiogenesis, the formation of new blood vessels within a tumor (or many other tissue types) has become a target of pharmacological research as well as industrial drug discovery [15]. Compounds with anti-angiogenic properties are of importance in the treatment and prevention of malignancies as well as other chronic diseases [16]. Though GA showed less antiangiogenic activity than captopril, the result obtained indicates that, in addition to direct cytotoxicity on cancer cells, this compound could also inhibit the proliferation of blood vessels in vivo, presumably with negative effect on tumor progression.

\section{Cell cycle analysis and apoptosis}

The low induction of apoptosis at the early stage of CCRF-CEM cells proliferation is in consistence with the caspase 3/7 activity study (Additional file 1: Figure S1), as low activation of these apoptosis effectors was noted upon $6 \mathrm{~h}$. However, higher apoptosis rates were finally obtained after $72 \mathrm{~h}$ with all tested concentrations, showing that apoptotic pathways are involved in the mechanism of GA-induced cell death in CCRF-CEM leukemia cells. Therefore, in vivo bioavailability and bioactivity studies are also to be carried out with this compound, as GA showed promising in vitro activities but induces apoptosis upon a long time period (72 h).

\section{Microarray analysis and signaling pathway profiling}

The cell cycle arrest in CCRF-CEM cells was early detected after $24 \mathrm{~h}$ and the down regulation of important genes such as CHK1 and WEE1, as reported above might plays a considerable role. This allegation is strengthened by the fact that one of the key players in cell cycle regulation such as GADD45 is also up-regulated following GA treatment (Additional file 1: Figure S1).

HSPA6 (heat shock $70 \mathrm{kDa}$ protein 6) and HIST1H2BD (histone cluster 1, H2bd) genes were found to be most upregulated upon GA treatment. In cooperation with other chaperones, Hsp70s stabilize preexistent proteins against aggregation and mediate the folding of newly translated polypeptides in the cytosol as well as within organelles. They bind extended peptide segments with a net hydrophobic character exposed by polypeptides during translation and membrane translocation, or following stress-induced damage (http://www.uniprot.org). Interestingly, $70 \mathrm{kDa}$ heat shock protein protects cells from ischemia and its expression is increased in consequence to hypoglycemia $[17,18]$. In addition, closely connected genes to HSPA6, HSPA1A and DNAJB2, were found to be upregulated in our anaylses. Whereas $H S P A 1 A$ is coding for heat shock $70 \mathrm{kDa}$ protein $1 \mathrm{~A} / 1 \mathrm{~B}, D N A J B 2$ has as protein product cochaperon Hsp40 (DNAJ in bacteria) which is essential for Hsp70 function [19]. Interesting genes which are up-regulated included FOSB and $J U N$. A combined up-regulation of these genes with Hsp70 mRNA was earlier observed in as stress response to high acceleration [20]. This finding also confirmed the assumption that GA might cause hypoxic stress. Through high acceleration an induction of ischemia can be observed [20]. Furthmore, dimerization of protein products of FOSB (a FOS family member) and JUN constitute the transcription factor AP1 which is activated by oxidative stress [21]. Surprisingly, a cofactor of JUN-activated transciption, $D D X 21$, belonged to one of the most down-regulated genes in our microarray analysis [22]. This findings give reason to speculate that GA might mimic under-supply of oxygen or glucose and, therefore, leads to apoptosis (see also Figure 2). Very interesting in the contest of the latter assumption was that GA inhibited angiogenesis (Figure 1). It would be worthwhile to investigate, whether the vascular endothelial growth factor (VEGF), its secretion or even the VEGF receptor are inhibited by GA leading to interrupted VEGF signaling, as normally VEGF is activated under hypoxic conditions [23]. Thereby, the fact that we did not observed any significant change in VEGF mRNA expression (See Additional file 1: Table S3) does not mean that VEGF signaling was not targeted by GA. VEGF protein expression can independently vary from corresponding mRNA amounts in the cell [24].

Certain histone mRNAs were also up-regulated after treatment with GA [HIST1H2BD, HIST2H2AC, HIST2H2AA4 (Table 3)]. This observation is surprising, as levels of histone mRNA usually increase during $\mathrm{S}$ phase, but decrease back to baseline level between the S-phase and mitosis [25]. This finding was also confirmed by our FACS analyses showing that cells treated with $1 \times \mathrm{IC}_{50}$ of GA for $72 \mathrm{~h}$ were more often arrested in the $S$ - or G2/M phases than untreated control cells (see also Figure 2.C2 and D2).

CD52 is a membrane protein which is discussed as target molecule for leukemia therapy [26]. Alemtuzumab is an antibody directly targeting CD52 and already approved for clinical use [27]. In our experiments, the mRNA of this protein was strongly up-regulated. A combined treatment of GA with Ametuzumab may possibly boost the apoptotic effect of both drugs, as GA might sensitize cells to Alemtuzumab by inducing CD52 expression and activating CD52 downstream mechanisms. This speculations merits further experimentation in the future.

$A C T B$ and $A C T B L 3$ belonged to the most downregulated genes. Beta-actin mRNA levels are known to be disturbed after ischemia [28], which is in line with our assumption that GA may mimic hypoxia. Another gene fitting to our hypothesis is PGAM1, which codes for phosphoglycerate mutase in glycolysis. Another gene coding for a protein similar to phosphoglycerate mutase 
processed protein was also down-regulated by GA, LOC728188. Down-regulation of glycolysis key molecules accompanied by hypoxic stress may destroy the entire energy production apperture ultimately leading to cell death. The mis-regulation in glyco-related mechanisms was also indicated by down-regulation of DHRS2, whose encoded protein preferentially binds to glucose and related sugars [29].

KPNA2 codes for importin alpha. This protein is a key player in the nuclear transport of macromolecules [30]. Moreover, HNRNPA1P2 is rarely investigated yet, but seems to be involved to mRNA transport from the nucleus to cytosol (according to UniProt database, www. uniprot.org). THOC4 encoding a more investigated mRNA transporter molecule was also significantly down-regulated. The THOC4 protein is part of the TREX complex, which specifically associates with spliced mRNA [31]. THOC4 is especially involved in nuclear export of Hsp70 transcripts [32].

Interestingly, RAB37 and TRAPPC6A encode also two proteins which are also involved to transport mechanisms (www.uniprot.org). They were also mis-regulated in their transcriptional activity after GA treatment. In summary, it seems that transport mechanisms are de-regulated as consequence of treatment with this compound.

Recapitulating, GA seems to cause hypoxia and hypoglycemia as several genes of these functions were affected. Furthermore, a considerable de-regulation of several protein- and mRNA-transporter genes was observed. The latter findings was also confirmed by Ingenuity Pathway Analyses of the microarray data pointing to "Molecular Transport" and "Protein Trafficking" with highest score (Table 3; Figure 3). In contrast, no molecules belonging to the other hits of Table 3 were found to be extremely up- or down-regulated.

In the signaling networks of Figures 3 and 4, more key players become apparent which do not belong to most mis-regulated genes in our investigation: HNRNPK, $L Y A R$ and $Y B X 1$. According to UniProt database, HNRNPK is involved in RNA processing and splicing. However, it is interesting from our point of view that it seems to be important for enhanced proliferation, as increased levels of HNRNPK mRNA correlates with increased proliferative activity [33]. LYAR is a gene involved in development and cell growth regulation and especially for leukemia cells, as mRNA levels are increased, but LYAR mRNA is not or only less expressed in cells of different healthy tissues, e.g. thymus, bone marrow, liver, heart, brain, kidney or spleen [34]. YBX1 encodes for a protein, YB-1, which is involved in many mechanisms: proliferation, mRNA processing, DNA repair, transcription, splicing and drug resistence [35]. The relation of YB-1 to drug resistance is due to its activation of the multidrug resistance gene, MDR1 [36]. In addition, $Y B X 1$ expression is also important for deregulation of the oncogene, $M Y C N$ [37] (Figure 3B).

$\mathrm{MYCN}$ is a prominent transcription factor important for tumorigenesis and chemotherapy. $M Y C N$ mRNA was found to be over-expressed in human tumor biopsies [38]. Directly correlated to this finding is the down-regulation of RUVBL1 mRNA (Figure 3B) encoding a protein which binds to MYC [39]. It is essential for cell proliferation. In addition, the RUVBL1 protein is associated with the activation of $\mathrm{NuA} 4$ histone acetyltransferase complex, which is associated to the de-regulated histone mRNAs mentioned above [40]. Finally, SGK1 up-regulation is very interesting, as the encoded protein might counteract the cytotoxic activity of GA and activate cell survival processes. It deserves more detailed investigations in the future to elucidate the connection between KPNA2 and SGK1, as recognition by importin alpha of Sgk (protein of SGK1 gene) might be necessary for nuclear import of activated SGK1 [41].

Furthermore, there is another connection between SGK1 (Figure 3B) and FOXO3A (Figure 4A). FOXO3A is a pro-apoptotic protein which is regulated by SGK1 [42]. FOXO3A has also an important role as transcription factor in oxidative stress reponse and cell protection [43]. Its role in cellular response to GA needs further investigations, because the activity of FOXO3A protein is controlled by phosphorylation, which was not measured in our mRNA expression profiling approach. Another prominent member involved in cell death mechanisms is YWHAG, which codes for 14-3-3 gamma protein [44]. 14-3-3 proteins are directly involved in apoptosis and cell survival regulation by inhibiting BAD and FOXO3A [45]. In summary, the signaling network shown in Figure 3B depicts genes related to cell survival.

The overall results of the present investigation strengthened the cytotoxic potency, the effect on cell cycle distribution, apoptosis, angiogenesis of Guieranone $\mathrm{A}$, and consequently give important information for the future investigation, that could lead to the potential use of this compound in cancer therapy.

\section{Additional file}

\footnotetext{
Additional file 1: Figure S1. Custumized regulated pathways affected by guieranone A treatment in CCRF-CEM cells (A). (B) Cell cycle: G2/M DNA damage checkpoint regulation; (C): ATM signaling. Table S2. Complete list of Signaling pathways with corresponding genes affected by treatment of CCRF-CEM cells with guieranone A. Table S3. Enzymatic activity of caspase 3/7 after $6 \mathrm{~h}$ treatment of CCRF-CEM cells. The activity of caspase $3 / 7$ is expressed as percentage \% relative to untreated cells. Figure S4. Top 10 signaling pathways affected by guieranone A treatment in CCRF-CEM cells. The evaluation of differentially expressed genes was performed using the Ingenuity Pathway Analysis software. (List of all pathways in supplemental data 8). Figure S5. Genes down- or up-regulated in CCRF-CEM cells after treatment guieranone A. Figure S6. Results of real-time reverse transcriptase PCR analysis. CCRF-CEM cells were treated with $I C_{50}$ concentration of guieranone for $24 \mathrm{~h}$,
} 
Transcriptional changes are expressed relative to G6PD. The mean value \pm SEM of three independent experiments is shown. Table S7. Functions associated with the networks for genes whose expression was affected by treatment with guieranone $A$.

\section{Competing interests}

No potential conflicts of interest were disclosed.

\section{Author's contributions}

Conceived and designed the experiments: VK, TEi, BW, BK and TE. Analyzed the data: VK, and TE. performed the experiments: VK, TEi, BK. Wrote the paper: VK, TEi and TE. All authors read and approved the final manuscript.

\section{Acknowledgements}

Authors are thankful to the National Herbarium of Cameroon (Yaounde) and Mr. Thabet Belkacemi for their technical supports. VK is also very grateful to the Department of Pharmaceutical Biology, Johannes Gutenberg University, Mainz, Germany and to the Alexander von Humboldt foundation for the 18 month postdoctoral fellowship in Germany.

Received: 4 May 2012 Accepted: 13 June 2012

Published: 20 June 2012

\section{References}

1. Jemal A, Bray F, Center MM, Ferlay J, Ward E, Forman D: Global cancer statistics. CA Cancer J Clin 2011, 61:69-90.

2. Mathers, Colin D, Cynthia Boschi-Pinto, Lopez AD, Murray CJL: Cancer incidence, mortality and survival by site for 14 regions of the world. Global Programme on Evidence for Health Policy Discussion 2001, http://www.who.int/entity/healthinfo/paper13.pdf.

3. Silva O, Gomes ET: Guieranone A, a naphthyl butenone from the leaves of Guiera senegalensis with antifungal activity. J Nat Prod 2003, 66:447-449

4. Fiot J, Sanon S, Azas N, Mahiou V, Jansen O, Angenot L, Balansard G, Ollivier E: Phytochemical and pharmacological study of roots and leaves of Guiera senegalensis J.F. Gmel (Combretaceae). J Ethnopharmacol 2006, 106:173-178.

5. McCulloch MWB, Barrow RA: A metalation strategy for the construction of functionalized naphthalenes: the first synthesis of guieranone A. Tetrahedron Lett 2005, 46:7619-7621.

6. Choudhary MI, Lannang AM, Ali S, Anjum S, Fun HK: (E)-1-(1,3,6,8Tetramethoxynaphthalen-2-yl)-but-2-en-1-one. Acta Cryst 2005, E61: o1015-01017.

7. O'Brien J, Wilson I, Orton T, Pognan F: Investigation of the Alamar Blue (resazurin) fluorescent dye for the assessment of mammalian cell cytotoxicity. Eur J Biochem 2000, 267:5421-5426.

8. Joshi SC, Verma AR, Mathela CS: Antioxidant and antibacterial activities of the leaf essential oils of Himalayan Lauraceae species. Food Chem Toxicol 2010, 48:37-40.

9. Wittmann J, Kugler W, Kaltner H: Cultivation of the early quail embryo: induction of embryogenesis under in vitro conditions. J Exp Zoo/ Supp/ 1997, 1:325-328.

10. D'Arcy PF, Howard EM: A new anti-inflammatory test, utilizing the chorioallantoic membrane of the chick embryo. Br J Pharmacol Chemother 1967, 29:378-387.

11. Marchesan M, Paper DH, Hose S, Franz G: Investigations of the anti- inflammatory activity of liquid extracts of Plantago lanceolata $\mathrm{L}$. Phytother Res 1998, 12:S33-S34.

12. Kuete V, Krusche B, Youns M, Voukeng I, Fankam AG, Tankeo S, Lacmata S, Efferth T: Anticancer activities of some Cameroonian spices and selected medicinal plant extracts. J Ethnopharmacol 2011, 134:803-812.

13. Eberwine J, Yeh H, Miyashiro K, Cao Y, Nair S, Finnell R, Zettel M, Coleman P: Analysis of gene expression in single live neurons. Proc Natl Acad Sci USA 1992, 89:3010-3014.

14. Boik J: Natural Compounds in Cancer Therapy. Minnesota: Oregon Medical Press; 2001.

15. Matter A: Tumor angiogenesis as a therapeutic target. Drug Discov Today 2001, 6:1005-1024.
16. Carmeliet P: Angiogenesis in health and disease. Nat Med 2003, 9:653-660.

17. Trost SU, Omens JH, Karlon WJ, Meyer M, Mestril R, Covell JW, Dillmann WH: Protection against myocardial dysfunction after a brief ischemic period in transgenic mice expressing inducible heat shock protein 70. J Clin Invest 1998, 101:855-862.

18. Shyu WC, Chen CP, Saeki K, Kubosaki A, Matusmoto Y, Onodera T, Ding DC, Chiang MF, Lee YJ, Lin SZ, Li H: m Hypoglycemia enhances the expression of prion protein and heat-shock protein 70 in a mouse neuroblastoma cell line. J Neurosci Res 2005, 80:887-894.

19. Fan CY, Lee S, Cyr DM: Mechanisms for regulation of Hsp70 function by Hsp40. Cell Stress Chaperones 2003, 8:309-316.

20. Shahed AR, Son M, Lee JC, Werchan PM: Expression of c-fos, c-jun and HSP70 mRNA in rat brain following high acceleration stress. J Gravit Physiol 1996, 3:49-56.

21. Piacentini L, Karliner JS: Altered gene expression during hypoxia and reoxygenation of the heart. Pharmacol Ther 1999, 83:21-37.

22. Westermarck J, Weiss C, Saffrich R, Kast J, Musti AM, Wessely M, Ansorge W, Séraphin B, Wilm M, Valdez BC, Bohmann D: The DEXD/H-box RNA helicase $\mathrm{RHII} / \mathrm{Gu}$ is a co-factor for c-Jun-activated transcription. EMBO J 2002, 21:451-460.

23. Berra $E$, Pagès $G$, Pouysségur J: MAP kinases and hypoxia in the control of VEGF expression. Cancer Metastasis Rev 2000, 19:139-145.

24. Kim BS, Chen J, Weinstein T, Noiri E, Goligorsky MS: VEGF expression in hypoxia and hyperglycemia: reciprocal effect on branching angiogenesis in epithelial-endothelial co-cultures. J Am Soc Nephrol 2002, 13:2027-2036.

25. Marzluff WF, Duronio RJ: Histone mRNA expression: multiple levels of cell cycle regulation and important developmental consequences. Curr Opin Cell Biol 2002, 14:692-699.

26. Kumar S, Kimlinger TK, Lust JA, Donovan K, Witzig TE: Expression of CD52 on plasma cells in plasma cell proliferative disorders. Blood 2003, 102:1075-1077.

27. Demko S, Summers J, Keegan P, Pazdur R: FDA drug approval summary: alemtuzumab as single-agent treatment for B-cell chronic lymphocytic leukemia. Oncologist 2008, 13:167-174.

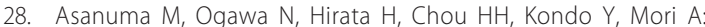
Ischemia-induced changes in alpha-tubulin and beta-actin mRNA in the gerbil brain and effects of bifemelane hydrochloride. Brain Res 1993, 600:243-248

29. Crouch E, Tu Y, Briner D, McDonald B, Smith K, Skov U, Hartshorn K: Ligand specificity of human surfactant protein $D$ : expression of a mutant trimeric collectin that shows enhanced interactions with influenza A virus. J Biol Chem 2005, 280:17046-17056.

30. Goldfarb DS, Corbett AH, Mason DA, Harreman MT, Adam SA: Importin alpha: a multipurpose nuclear-transport receptor. Trends Cell Biol 2004, 14:505-514.

31. Masuda S, Das R, Cheng H, Hurt E, Dorman N, Reed R: Recruitment of the human TREX complex to mRNA during splicing. Genes Dev 2005, 19:1512-1517.

32. Orlova AV, Kopytova DV, Krasnov AN, Nabirochkina EN, Ilyin YV, Georgieva SG, Shidlovskii YV: Transcriptional factor ENY2 promotes recruitment of the THO complex to the hsp70 gene of Drosophila melanogaster. Dokl Biochem Biophys 2010, 434:227-231.

33. Ostrowski J, Bomsztyk K: Nuclear shift of hnRNP $\mathrm{K}$ protein in neoplasms and other states of enhanced cell proliferation. $\mathrm{Br} \mathrm{J}$ Cancer 2003, 89:1493-1501

34. Su L, Hershberger RJ, Weissman IL: LYAR, a novel nucleolar protein with zinc finger DNA-binding motifs, is involved in cell growth regulation. Genes Dev 1993, 7:735-748.

35. Feng Q, Huang S, Zhang A, Chen Q, Guo X, Chen R, Yang T: Y-box protein 1 stimulates mesangial cell proliferation via activation of ERK1/2. Nephron Exp Nephrol 2009, 113:e16-e25.

36. Chattopadhyay R, Das S, Maiti AK, Boldogh I, Xie J, Hazra TK, Kohno K, Mitra S, Bhakat KK: Regulatory role of human AP-endonuclease (APE1/Ref-1) in YB-1-mediated activation of the multidrug resistance gene MDR1. Mol Cell Biol 2008, 28:7066-7080.

37. Weidensdorfer D, Stöhr N, Baude A, Lederer M, Köhn M, Schierhorn A, Buchmeier S, Wahle E, Hüttelmaier S: Control of c-myc mRNA stability by IGF2BP1-associated cytoplasmic RNPs. RNA 2009, 
15:104-115

38. Chiecchio L, Dagrada GP, White HE, Towsend MR, Protheroe RK, Cheung KL, Stockley DM, Orchard KH, Cross NC, Harrison CJ, Ross FM: UK myeloma forum: frequent upregulation of MYC in plasma cell leukemia. Genes Chromosomes Cancer 2009, 48:624-636.

39. Wood MA, McMahon SB, Cole MD: An ATPase/helicase complex is an essential cofactor for oncogenic transformation by c-Myc. Mol Cell 2000, 5:321-330.

40. Doyon Y, Selleck W, Lane WS, Tan S, Côté J: Structural and functional conservation of the NuA4 histone acetyltransferase complex from yeast to humans. Mol Cell Biol 2004, 24:1884-1896.

41. Maiyar AC, Leong ML, Firestone GL: Importin-alpha mediates the regulated nuclear targeting of serum- and glucocorticoid-inducible protein kinase (Sgk) by recognition of a nuclear localization signal in the kinase central domain. Mol Biol Cell 2003, 14:1221-1239.

42. Brunet A, Park J, Tran H, Hu LS, Hemmings BA, Greenberg ME: Protein kinase SGK mediates survival signals by phosphorylating the forkhead transcription factor FKHRL1 (FOXO3a). Mol Cell Biol 2001, 21:952-965.

43. Lehtinen MK, Yuan Z, Boag PR, Yang Y, Villén J, Becker EB, DiBacco S, de la Iglesia N, Gygi S, Blackwell TK, Bonni A: A conserved MST-FOXO signaling pathway mediates oxidative-stress responses and extends life span. Cell 2006, 125:987-1001.

44. Horie M, Suzuki M, Takahashi E, Tanigami A: Cloning, expression, and chromosomal mapping of the human 14-3-3gamma gene (YWHAG) to 7q11.23. Genomics 1999, 60:241-243.

45. Rosenquist M: 14-3-3 proteins in apoptosis. Braz J Med Biol Res 2003, 36:403-408

doi:10.1186/1747-1028-7-16

Cite this article as: Kuete et al:: Cytotoxicity, anti-angiogenic, apoptotic effects and transcript profiling of a naturally occurring naphthyl

butenone, guieranone A. Cell Division 2012 7:16.

\section{Submit your next manuscript to BioMed Central and take full advantage of:}

- Convenient online submission

- Thorough peer review

- No space constraints or color figure charges

- Immediate publication on acceptance

- Inclusion in PubMed, CAS, Scopus and Google Scholar

- Research which is freely available for redistribution 